\title{
PEMIKIRAN SASMITANING SUKMA TENTANG PEMBAHARUAN TASAWUF DAN IMPLIKASINYA TERHADAP GERAKAN DAKWAH DI KULONPROGO
}

\author{
Moh. Abdul Kholiq Hasan, Abdurrohim \\ Fakultas Usuluddin dan Dakwah IAIN Surakarta Sekolah Pascasarjana Universitas \\ Islam Negeri Sunan Kalijaga Yogyakarta, Magister Pendidikan Islam Sekolah \\ Pascasarjana Universitas Muhammadiyah Surakarta \\ Email: hasanuniversitas@gmail.com, abdurohim@gmail.com
}

\begin{abstract}
Tasawuf (mysticism) is generally considered as deviation by most of Muslim community itself. One of religious figures who is active in preaching and interesting in Indonesia as well as having a big influence because of this thought is Ki H SS. Ki H SS is able to present the tasawuf teaching based on al Quran verses and Hadist. An interesting thing to be analyzed is "What is Ki H SS' thought in the renewal of tasawuf and the implementation of his thought on the preaching movement and its influence on the society's religious experience?". This research is a field research focusing on the results of data collection from several results of observation and interview that have been determined. Besides, this research also uses references either from books or journals closely related to the research problems. The approach used in this research is historical-sociological approach. The results of this research are : 1) Ki H SS' thought has much tendency to tasawuf. Ki H SS' thought also has much tendency to focus on the internal aspect than to external/physical aspect. Tasawuf he understood is an effort to be able to know Allah through purifying self in the matter of aqidah (Islamic creed), worship or behavior; 2) The implementation of Ki H SS' thought are, among other, the change in the society' thought pattern, from animism and dynamism to tauhid (the oneness of God), increasing harmony in the society, the removal of culture which trapped into polytheism act, bid'ah (heresy) and khurufat (superstition), the emergence of awareness on education by the existence of formal school 'Muhammadiyah Elementary School' and Islamic Boarding School, the society had more understanding on the importance of obeying to God and to the leaders, change in vision and mission of life into knowing God closer, etc.
\end{abstract}

Keywords: The renewal of tasawuf, The thought of Ki H SS, The implementation of thought.

Abstrak: Tasawuf pada umumnya dianggap sesat oleh sebagian besar dari kalangan muslim sendiri. Salah satu tokoh agama yang giat berdakwah dan menarik di Indonesia serta memiliki pengaruh besar karena pemikiran dakwahnya di masyarakat yaitu Ki $H$. Sasmitaning Sukma (selanjutnya bisa disebut Ki H SS). Ki H SS ini mampu menampilkan ajaran tasawuf yang berlandaskan dari ayat-ayat al Quran dan Hadits. Hal yang menarik untuk dianalisis adalah apa pemikiran Ki H SS dalam pembaharuan pemikiran tasawuf dan implementasi dari pemikirannya terhadap gerakan dakwah dan pengaruhnya terhadap pengamalan agama masyarakat. Penelitian ini merupakan penelitian lapangan (field research), penelitian ini memfokuskan pada hasil pengumpulan data dari beberapa hasil observasi dan wawancara yang telah ditentukan. Selain itu penelitan ini juga menggunakan referensi-referensi berupa buku maupun dari jurnal yang erat kaitannya dengan permasalahan penelitian. Pendekatan yang digunakan dalam penelitian ini adalah 
pendekatan historis sosiologis. Hasil penelitian ini, yaitu: 1)Pemikiran Ki H SS ini lebih cenderung kepada tasawuf. Pemikiran Ki H SS ini juga lebih cenderung menekankan aspek batin atau jiwa daripada aspek jasmani. Tasawuf yang ia fahami adalah usaha untuk bisa mengenal Allah dengan melalui pembersihan diri dalam masalah aqidah, ibadah maupun akhlaq.; 2) Implementasi dari pemikiran Ki H SS antara lain perubahan pola pikir masyarakat, dari animisme dinamisme kepada tauhid, kerukunan dalam masyarakat menjadi semakin tinggi, hilangnya budaya yang menjerumuskan kepada amalan syirik, bida'ah dan khurafat, timbulnya kesadaran tentang pendidikan dengan adanya sekolah formal SD Muhammadiyah dan Pondok Pesantren, masyarakat menjadi paham akan pentingnya ketaatan kepada Tuhan dan kepada pemimpin, perubahan visi misi hidup ke arah taqorrub ilallah, dan lain-lain.

Kata kunci: Pembaharuan tasawuf, pemikiran Ki H SS, implementasi pemikiran

\section{PENDAHULUAN}

Tokoh agama yang giat berdakwah dan menarik di Indonesia serta memiliki pengaruh besar karena pemikiran dakwahnya di masyarakat yaitu Kiai Haji Sasmitaning Sukma (selanjutnya bisa disebut Ki H SS). Dia merupakan tokoh besar dari daerah Kulon Progo di daerah bukit Menoreh sisi utara, daerah perbatasan Magelang, Jawa Tokoh agama yang giat berdakwah dan menarik di Indonesia serta memiliki pengaruh besar karena pemikiran dakwahnya di masyarakat yaitu Kiai Haji Sasmitaning Sukma (selanjutnya bisa disebut Ki H SS). Daerah ini merupakan daerah terisolir yang sulit dijangkau oleh kendaraan. Penduduk di daerah ini sebagian besar adalah petani atau pekebun kopi atau cengkeh.

Ki H SS melakukan perubahan pola pikir yang dilandasi dengan ilmu tasawuf dan juga merupakan tokoh yang menentang ajaran gereja dimasanya yang didukung pemerintah Belanda. Hal itu dia wujudkan dalam melawan upaya kristenisasi kepada umat Islam. Selain itu dia juga merupakan tokoh penggerak dakwah yang mengajarkan dengan menggunakan istilah bahasa jawa. Selain itu dia juga menggunakan beberapa istilah serta beberapa lambang singkat untuk memudahkan masyarakat memahami pemikiran dakwahnya.
Beberapa kondisi seperti rendahnya pendidikan, lemahnya pemahaman agama dan akses ekonomi yang memburuk merupakan sebab tersendiri akan adanya gerakan pemikiran dakwah Ki H SS. Hal ini pula juga telah digunakan adanya upaya misionaris kristen untuk melaksakan progam mereka. Gerakan mereka didukung dari pemerintah kolonial dengan mendirikan, mendirikan Rumah Sakit, Sekolah, Panti Asuhan di daerah Boro, Sidoharjo, Samigaluh, Kulon Progo.

Penyampaian pemikiran dalam dakwahnya telah menarik ribuan orang disekitarnya. Namun, kegigihannya dalam dakwah bukan berarti tanpa halangan. Hasutan dan permintaan untuk adanya pembubaran pemikiran dakwahnya sempat terjadi. Permintaan ini dipelopori oleh beberapa orang yang cemburu dan tidak suka pemikiran $\mathrm{Ki} \mathrm{H}$ SS yang berkembang.

Akulturasi budaya Jawa Pra Islam oleh kelompok keagamaan saat itu banyak memunculkan percampuran antara ajaran Islam dengan kepercayaan lokal (Hindu dan Budha ) serta tumbuh suburnya kesyirikan. Lebih dari itu Kolonialisme Belanda telah menjadikan sekelompok orang Islam lebih mendewakan harta, mereka rela menjadi antek-antek Belanda dengan imbalan kemewahan dunia. Sehingga lupa dengan tujuan hakiki 
penciptaan manusia di dunia. Kondisi kaum muslimin yang demikian ini pula mendorong $\mathrm{Ki}$ H SS melakukan gerakan dakwah pemurnian aqidah yang bersumber kepada Tauhid Uluhiyyah.

Iahanyamengumpulkanparapemuda dari masyarakat sekitar untuk dididik dan digembleng dengan pendalaman agama yang menitik beratkan pada masalah aqidah, tazkiyatun nafs, dan semangat jihad melalui jalan dakwah. Para kader ini diharapkan mampu menyebarkan ide-ide dan pemikran Ki H SS kepada masyarakat muslim. Diantara murid-muridnya ada sembilan orang yang dianggap mampu melanjutkan pemikiran dan gagasan Ki H SS. Sembilan murid ini kemudian diangkat sebagai murid senior tempat berguru para jamaah pengikutnya dengan gelar mujaddid. Ki H SS ini merupakan tokoh Muhammadiyah dan sekaligus tokoh dari Masyumi. Dia juga merupakan murid dari K. H Amad Dahlan. Sehingga pemikirannya juga tidak berbeda dengan gurunya terutama tentang ajaran tauhid, serta memberantas bid'ah, tahayul dan khurafat. Walaupun demikian, terdapat perbedaan dalam hal metode pendekatan dakwahnya. Dia menggunakan metode pendekatan dakwah yang bercorak tasawuf.

Kajian dan kegelisahan akademik yang menarik diteliti dari pemikiran tasawuf K. H SS adalah adanya perbedaan dengan tasawuf pada umumnya. Tasawuf pada umumnya dianggap sesat oleh sebagian besar dari kalangan muslim sendiri. Namun Ki H SS ini mampu menampilkan ajaran tasawuf yang berlandaskan dari ayat-ayat al Quran dan Hadits. Dalam hal ini, pemikiran tasawuf dari Ki H SS perlu untuk dianalisis lebih lanjut. Selain itu, hal yang menarik untuk dianalisis adalah implementasi dari pemikirannya terhadap gerakan dakwah dan pengaruhnya terhadap pengamalan agama masyarakat.
Tujuan Penelitian adalah untuk mengetahui pemikiran Ki H SS dalam pembaharuan tasawuf dan mengetahui implementasi dari pemikiran $\mathrm{Ki} \mathrm{H}$ SS terhadap gerakan dakwah dan pengaruhnya terhadap pengamalan Agama Masyarakat.

\section{METODE PENELITIAN}

Jenis penelitian ini merupakan penelitian lapangan (field research). Data pada penelitian ini bersumber dari data hasil observasi dan wawancara di lapangan. Penelitian ini menggunakan data sekunder yang sudah dalam bentuk jadi, seperti dokumen dan publikasi. Sumber data dalam penelitian ini dibedakan menjadi dua macam, yaitu: Sumber data primer dan sumber data sekunder. Sumber Data primer dalam penelitan ini bersumber dari tulisantulisan tokoh tersebut dan atau dari tulisan-tulisan para muridnya yang masih hidup. Sedangkan sumber data sekunder yang digunakan dalam penelitian ini adalah tulisan para penulis lain tentang dirinya dalam bentuk penelitian dan buku, sebagaimana yang terdapat dalam kepustakaan. Sumber data tertulis dilacak melalui pembacaan buku-buku, artikel, jurnal, dokumentasi, dan atau dokumen lain yang berkaitan dengan penelitian.

Sifat penelitian ini bersifat deskriftif analitis. Pendekatan yang digunakan dalam penelitian ini adalah pendekatan historis sosiologis. Semua data yang sudah terkumpul baik dari observasi, wawancara dan pustaka kemudian diklarifikasi menurut sifat-sifatnya masingmasing, kemudian diinterpretasikan, dan dianalisis menggunakan analisis kualitatif. Sehingga ditemukan jawaban dari permasalahan penelitian secara tepat. Analisis data dilakukan dengan cara menelaah data dengan teori yang ada dalam penelitian.. 


\section{HASIL DAN PEMBAHASAN Tasawuf dalam Tinjaun Umum}

Secara estimologis para ahli berselisih pendapat tentang asal kata tasawuf. Sebagian menyatakan bahwa tasawuf berasal dari șuffah yang berarti emper masjid Nabawi yang didiami oleh sebagian sahabat Anshar. Sedangkan yang lain ada yang menyatakan berasal dari șaf, yang berarti barisan. Ada juga juga yang mengatakan berasal dari kata sufanah yaitu nama kaum yang bertahan tumbuh di padang pasir. ${ }^{1}$ Terakhir ada yang mengatakan berasal dari bahasa Yunani theolosofi yang berarti Ilmu ketuhanan. ${ }^{2}$ Kemudian yang menyatakan berasal dari suf (bulu domba) dan orang yang berpakain bulu domba disebut mutasawwif, perilakunya disebut tasawuf. ${ }^{3}$ Selain itu, Hamka juga menambahkan bahwa tasawuf dari perkataan sifa yang artinya suci bersih, ibarat kilat kaca. ${ }^{4}$ Buya Hamka menambahkan bahwa kata "sufi" bukanlah bahasa Arab, namun bahasa Yunani yang di-Arab-kan. Sufi menurutnya berasal dari kata theosofie, artinya ilmu ke-Tuhanan. Kata tersebut kemudian di ucapakan orang Arab dan berubah menjadi tasawuf. ${ }^{5}$

Dunia tasawuf mengalami pasang surut luar biasa dalam sejarah Islam. Secara empirik menurutnya, latar belakang yang meruntuhkan supremasi tasawuf dalam ilmu-ilmu Islam disebabkan beberapa faktor antara lain yaitu: 1) intelektualisme-skriptual yang

1 Dalam buku Tasawuf Modern, șufanah ialah sebangsa kayu yang mersik tumbuh di padang pasir tanah Arab; Buya Hamka, Tasawuf Modern, (Jakarta: Republika, 2015), hlm. 1.

2 Pendapat dijelaskan oleh oleh Buya Hamka. Buya Hamka menjelaskan setengah ahli bahasa dan riwayat terutama di zaman akhir ini mengatakan bahwa kata "sufi" bukan bahasa Arab. Namun bahasa Yunani yang di-Arab-kan sehingga menjadi tasawuf; Buya Hamka, Tasawuf Modern, (Jakarta: Republika, 2015), hlm. 1.

3 Amin Syukur, Menggugat Tasawuf ..., hlm. 8.

4 Buya Hamka, Tasawuf Modern ..., hlm. 1.

5 Buya Hamka, Tasawuf Modern ..., hlm. 1-2. stagnan; 2) faktor-faktor politik yang memanfaatkan legitimasi ajaran Islam dan golongan-golongan keagamaan untuk kepentingan kekuasaan. Walaupun demikian, supremasi tasawuf kembali ada karena beberapa sebab antara lain, yaitu 1) doktrin-doktrin formalismetekstual mengalami kegagalan dalam menghadapi spirit paling agung dalam ajaran Qur'an dan Sunnah; 2) penggalian kembali nilai-nilai khazanah tradisional generasi awal seperti nilai-nilai etik, estetik untuk pencerahan spriritualisme kontemporer. ${ }^{6}$

Berbagai literatur menyebutkan bahwa ajaran zuhud dalam Islam adalah benih munculnya tasawuf sejak masa Nabi Muhammad. Hal ini dimulai dari pendapat Ibnu al-Jauzi dan Ibnu Khaldun yang mengatakan bahwa kerohanian dalam Islam dibagi menjadi dua, yakni zuhud dan tasawuf. Kedua istilah itu sebenarnya belum ada pada masa nabi Muhammad, namun kata zuhud dapat ditemui dalam al Quran Surat Yusuf ayat $20 .^{7}$ Pada zaman Nabi mereka para sufi dikenal orang-orang yang terhindar dari syirik dan pola kehidupan jahiliyah, selalu meresapi al Qor'an dan meresapi al Qur'an. ${ }^{8}$

$6 \quad$ An Naisabury, Risalah Qusyairiyah ..., hlm. V.

7 Amin Syukur, Menggugat Tasawuf ..., hlm. 2829.

8 Terdapat nama-nama sahabat yang menjauhkan diri dari kehidupan duniawi, seperti Abdullah Ibn Umar, Abu Dzar Al-Ghiffari, Bahlul Ibn Zuhaib, Kahmas Al-Hilali. Mereka menjahui dunia dengan banyak berpuasa di siang hari, dan shalat serta membaca al Qur'an di malam hari; Amin Syukur, Menggugat Tasawuf ..., hlm. 29. Dalam buku Munir Amin dijelaskan bahwa pada mulanya tasawuf merupakan perkembangan dari pemahaman tentang makna institusiinstitusi Islam. Sejak zaman sahabat dan tabiin, kecenderungan pendangan orang terhadap Islam secara analisis sudah muncul. Ajaran Islam dipandang dari dua aspek, yaitu aspek lahiriyah dan aspek batiniyah. Atau aspek "luar"dan aspek "dalam". Pendalaman dan pengalaman aspek "dalam" mulai terlihat sebagai hal yang paling utama, namun tanpa mengabaikan aspek "luar" 
Dalam perkembangannya pada masa khulafaur ar-rasyidin dikalangan umat Islam, terdapat faktor internal lainnya yang menjadi faktor munculnya tasawuf adalah reaksi kaum muslim terhadap sistem sosial, politik, budaya, dan ekonomi. Pada satu sisi terdapat kemakmuran, tetapi di pihak lain terjadi pertikaian politik umat Islam yang bermula dari fitnah al kubra yang menimpa Khalifah Ustman bin Affan. Pertikain ini kemudian menimbulkan perang saudara antara Ali bin Abi Thalib dan Muawiyyah. ${ }^{9}$ Dari peristiwa ini dipahami bahwa telah terjadi kemerosotan akhlak. Sehingga sahabat-sahabat, pemuka-pemuka Islam yang masih ada kemudian berpikir dan berusaha membangkitkan kembali ajaran Islam. ${ }^{10}$

Akibatnya, sebagian tokoh agama mengambil jarak dengan tokoh politik. ${ }^{11}$ Mereka kemudian pulang masuk masjid, kembali mendengarkan targib dan tarhib mengenai keindahan hidup zuhud dan lain sebagainya. ${ }^{12}$ Dari sinilah nilai-nilai kehidupan tasawuf di kalangan umat Islam terus berkembang dengan pesat, karena percaturan tasawuf dengan berbagi unsur, baik unsur dari dalam Islam sendiri maupun dari non Islam yang

yang dimotivasi untuk membersihkan jiwa. Tanggapan perenungan mereka lebih beriorentasi pada aspek "dalam" yaitu cara hidup yang lebih mengutamakan rasa, keagungan Tuhan dan kebebasan dari egoisme; Samsul Munir Amin, Ilmu Tasawuf ..., hlm. 123-124.

9 Samsul Munir Amin, Ilmu Tasawuf ..., hlm. 123124; Dijelaskan pula oleh Amin Syukur pada masa Khula Al-Rasyidin ketiga yang pertama, istilah qurra dipakai sebagai panggilan bagi pengkaji al Qur'an. Setelah kematian Ali dan Husain, muncul orang-orang yang mengaku dirinya banyak dosa sehingga mereka kemudian bertobat dan mereka disebut tawwabin. Ada juga buka'in karena selalu menguncurkan air mata kepedihan, ada juga qașsas (pendongeng), Nussak (ahli ibadah), rabbaniyah (ahli ketuhanan), dan sebagainya. Amin Syukur, Menggugat Tasawuf ..., hlm. 29.

$10 \quad$ Ibid ..., hlm. 29.

11 Samsul Munir Amin, Ilmu Tasawuf ..., 123.

12 Amin Syukur, Menggugat Tasawuf ..., hlm. 29. mempengaruhi kehidupan spiritual umat Islam. ${ }^{13}$

Perkembangan Islam tasawuf dalam Islam telah mengalami beberapa fase. Pertama, fase asketisme (zuhud) yang tumbuh pada abad I dan II hijriah. Sikap asketisme banyak dipandang sebagai pengantar munculnya tasawuf. ${ }^{14}$ Pada abad ke III hijriah, para sufi mulai menaruh perhatian terhadap hal yang berkaitan dengan tingkah laku. Abu alWafa menjelaskan sebagaimana dikutip oleh Amin Syukur bahwa tasawuf abad III dan IV lebih mengarah kepada ciri psikomoral, dan perhatiannya diarahkan kepada pada moral serta tingkah laku. Sementara kecenderungan metafisis yang muncul tidak secara jelas. Pada abad ke V Hijriah disebut dengan periode konsolidasi oleh Annemarie Schimmael. Hal ini karena cenderung mengadakan pembaharuan, yakni periode yang ditandai pemantapan dan pengembalian tasawuf ke landasannya, al-Quran dan alhadits. Sejak abad ke VI Hijriah, sebagai akibat kepribadian Al-Ghazali yang begitu besar, pengaruh tasawuf sunni meluas ke seluruh pelosok dunia Islam. Keadaan ini memberi peluang bagi munculnya para tokoh sufi yang mengembangkan tarekat-tarekat untuk mendidik para murid mereka seperti Sayyid Ahmad Ar Rifa'i dan Sayyid Abdul QadirAl Jailani. ${ }^{15}$ Adapun tahapan perkembangan tasawuf yang terakhir adalah masa pemurnian. Masa ini terjadi pada abad VII Hijriah. Pada masa ini muncul tokoh, Ibnu Taimiyah. Dia dengan lantang menyerang penyelewengan-penyelewengan para sufi.

13 Samsul Munir Amin, Ilmu Tasawuf..., hlm. 123.

14 Mereka menjalankan konsep asketis dalam kehidupan, yaitu tidak mementingkan makanan, pakaian, dan tempat tinggal. Mereka lebih banyak beramal untuk hal-hal yang berkaitan dengan kehidupan akhirat, yang lebih memusatkan diri pada jalur kehidupan dan tingkah laku yang asketis. Samsul Munir Amin, Ilmu Tasawuf..., hlm. 124.

15 Ibid ..., hlm. 125. 
Pembaharuan Pemikiran Tasawuf dan Implikasi Terhadap Gerakan Dakwah Ki H. Sasmitaning Sukma

Pemikiran Ki HSS ini lebih cenderung kepada tasawuf. Pemikiran Ki H SS ini juga lebih cenderung menekankan aspek batin atau jiwa daripada aspek jasmani. Tasawuf yang ia fahami adalah usaha untuk bisa mengenal Allah dengan melalui pembersihan diri dalam masalah aqidah, ibadah maupun akhlaq. Purifikasi aqidah dilakukan dengan menanamkan pemahaman tauhid sampai pada tataran tauhid uluhiyyah; serta menjauhi perbuatan syirik. Tahayul, dan khurafat.

Dalam masalah ibadah, ia menekankan al-ruju' ila al-Qur'an wa alhadits. Ia menolak faham tasawuf yang meninggalkan syariat ketika sudah mencapai tataran ma'rifat. Konsekuensi dari hal ini ia menyerukan untuk menjauhi perbuatan bid'ah dalam masyarakat. Sedangkan dalam masalah akhlak, ia mengajak gerakan pembersihan pribadi dari akhlak tercela, dan menghiasi diri dengan akhlak mulia; seperti sabar, syukur, zuhud, tawakkal, ikhlas dan ridho terhadap segala ketentuan Allah.

Ia juga menyadarkan masyarakat tentang hakikat kehidupan yang sebenarnya. Bahwa kebahagiaan hidup yang hakiki adalah kelak di akhirat, ketika bisa memandang wajah Allah. Oleh karena itu manusia tidak boleh terlena dengan kehidupan dunia yang fana dan sementara. Tujuan, visi dan misi hidup seorang mukmin adalah dari Allah, bersama Allah dan kembali kepada Allah. Ajaran pemahaman agama Ki H SS tersebut dikemas dalam bahasa Jawa, dalam kumpulan catatan pelajarannya.

Implementasi dari pemikiran dan gerakan Ki H SS ini terlihat jelas dalam berbagai sisi. Yang termasuk dari hal ini, antara lain, yaitu: perubahan pola pikir masyarakat, dari animisme dinamisme kepada tauhid, kerukunan dalam masyarakat menjadi semakin tinggi, hilangnya budaya yang menjerumuskan kepada amalan syirik, bida'ah dan khurafat, timbulnya kesadaran tentang pendidikan dengan adanya sekolah formal SD Muhammadiyah dan Pondok Pesantren, masyarakat menjadi paham akan pentingnya ketaatan kepada Tuhan dan kepada pemimpin, perubahan visi misi hidup ke arah taqorrub ilallah, dan lain-lain.

Dalam melakukan gerakan dakwahnya, ia juga mendapatkan beberapa orang yang menolak pemikirannya, bahkan adanya permintaan untuk dibubarkan. Pemikiran Ki H SS ini juga menyadarkan masyarakat terhadap ilmu dan pentingnya masjid sebagai pusat kegiatan umat. Kesadaran akan pentingnya ilmu nampak dalam dukungan masyarakat atas pendirian sekolah yang dipeloporinya dan atau muridnya. Hal yang penting dan pokok sebagai wujud implementasi pemikiran Ki SS ini adalah adanya pemahaman aqidah yang benar dalam masyarakat dan bersihnya masyarakat dari penyelewengan aqidah yang tidak benar.

\section{PENUTUP}

Pemikiran Ki HSS ini lebih cenderung kepada tasawuf. Pemikiran Ki H SS ini juga lebih cenderung menekankan aspek batin atau jiwa daripada aspek jasmani. Tasawuf yang ia fahami adalah usaha untuk bisa mengenal Allah dengan melalui pembersihan diri dalam masalah aqidah, ibadah maupun akhlaq.

Implementasi dari pemikiran dan gerakan Ki H SS ini terlihat jelas dalam berbagai sisi. Yang termasuk dari hal ini, antara lain, yaitu: perubahan pola pikir masyarakat, dari animisme dinamisme kepada tauhid, kerukunan dalam masyarakat menjadi semakin tinggi, hilangnya budaya yang menjerumuskan kepada amalan syirik, bida'ah dan khurafat, timbulnya kesadaran tentang pendidikan dengan adanya sekolah 
formal SD Muhammadiyah dan Pondok Pesantren, masyarakat menjadi paham akan pentingnya ketaatan kepada Tuhan dan kepada pemimpin, perubahan visi misi hidup ke arah taqorrub ilallah, dan lain-lain.

Saran kepada para cendekiawan muslim diharapkan untuk meneliti lebih mendalam tentang ajaran Ki H SS agar bisa memahami pemikiran Islam para tokoh Ulama Nusantara. Disarankan kepada para ulama, kaum cerdik muslim dan pemuka-pemuka agama Islam yang memiliki semangat pembaharuan kepada umat untuk berupaya membersihkan umat dari pemahaman-pemahaman dan amalan-amalan khurafat, takhayul dan bid'ah. Disarankan kepada seluruh lembaga-lembaga atau badan-badan keagamaan Islam dapat memiliki suatu progam kerja yang nyata dalam pemurnian dan pembersihan aqidah dari penyakit syirik, bid'ah dan tahayul dalam masyarakat. Sedangkan untuk orang tua, disarankan dapat memberikan kesempatan kepada generasi muda agar dapat belajar ilmu agama slam secara lebih mendalam.

\section{DAFTAR PUSTAKA}

Amin, Samsul Munir, Ilmu Tasawuf, Jakarta: Amzah, 2014

Asyari, Suadi, Nalar Politik NU dan Muhammadiyah, terj. Mohammad Rapik, Yogyakarta: LkiS, 2010

Kartanegara, Mulyadi, Menyelami Lubuk Tasawuf, Jakarta: Erlangga, 2006

Ki Haji Mursyid, Nginjen Wadining dumadi Tauhidul Uluhiyyah, ttp., ttp.

Syukur, Amin, Menggugat Tasawuf Sufisme Tanggung Jawab Sosial Abad 21, Yogyakarta: Pustaka Pelajar, 2012

Mudzar, Mohammad Atho, Fatwa-Fatwa Majelis Ulama Indonesia: Sebuah studi tentang Pemikiran Hukum Islam di Indonesia 1975-1988, terj. Soedarso Soekarno, Jakarta: INIS, 1993

Munir, Samsul, Sejarah Peradaban Islam, Jakarta: Amzah, 2010

Asyari, Suadi, Nalar Politik NU dan Muhammadiyah, terj. Mohammad Rapik, Yogyakarta: LkiS, 2010

Hamka, Buya, Tasawuf Modern, Jakarta: Republika, 2015 